\title{
Modal Analysis of a Steel Radial Gate Exposed to Different Water Levels
}

\author{
Krzysztof Brusewicz, Witold Sterpejkowicz-Wersocki, \\ Robert Jankowski \\ Faculty of Civil and Environmental Engineering, Gdańsk University of Technology, ul. Gabriela \\ Narutowicza 11/12, 80-233 Gdańsk, e-mails: Corresponding author krzysztof.brusewicz@pg.gda.pl
}

(Received April 04, 2017; revised July 05, 2017)

\begin{abstract}
With the increase in water retention needs and planned river regulation, it might be important to investigate the dynamic resistance of vulnerable elements of hydroelectric power plants, including steel water locks. The most frequent dynamic loads affecting hydroengineering structures in Poland include vibrations caused by heavy road and railway traffic, piling works and mining tremors. More destructive dynamic loads, including earthquakes, may also occur in our country, although their incidence is relatively low. However, given the unpredictable nature of such events, as well as serious consequences they might cause, the study of the seismic resistance of the steel water gate, as one of the most vulnerable elements of a hydroelectric power plant, seems to be important.

In this study, a steel radial gate has been analyzed. As far as water gates are concerned, it is among the most popular solutions because of its relatively small weight, compared to plain gates. A modal analysis of the steel radial gate was conducted with the use of the FEM in the ABAQUS software. All structural members were modelled using shell elements with detailed geometry representing a real structure. Water was modelled as an added mass affecting the structure. Different water levels were used to determine the most vulnerable state of the working steel water gate.

The results of the modal analysis allowed us to compare the frequencies and their eigenmodes in response to different loads, which is one of the first steps in researching the dynamic properties of steel water gates and their behaviour during extreme dynamic loads, including earthquakes.
\end{abstract}

Key words: modal analysis, radial gate, dynamic loads

\section{Introduction}

The past few years have shown that Poland needs a better water management system. Long dry summers coupled with short rainless winters test our country's small water reserves. With the climate changing, our focus on retaining water should be much greater than it is now. Hydroengineering structures, like reservoirs or water power plants, should be maintained and modernized to prevent any damage to our 
already limited water management capabilities. Additional reservoirs, as well as regulation of Poland's relatively wild rivers, should be prioritized. With the increase in water retention needs and planned river regulation, it might be important to investigate the dynamic resistance of vulnerable elements of hydroelectric power plants, including steel water locks. Various studies are conducted all over the world, including Poland. A variety of modal analyses, simulations, experimental analyses, as well as dynamic-property research have been conducted (see Anami et al 2012, Liu et al 2011, Cai and Zhang 2011, Pani and Bhattacharyya 2008, Wójcicki et al 2016)

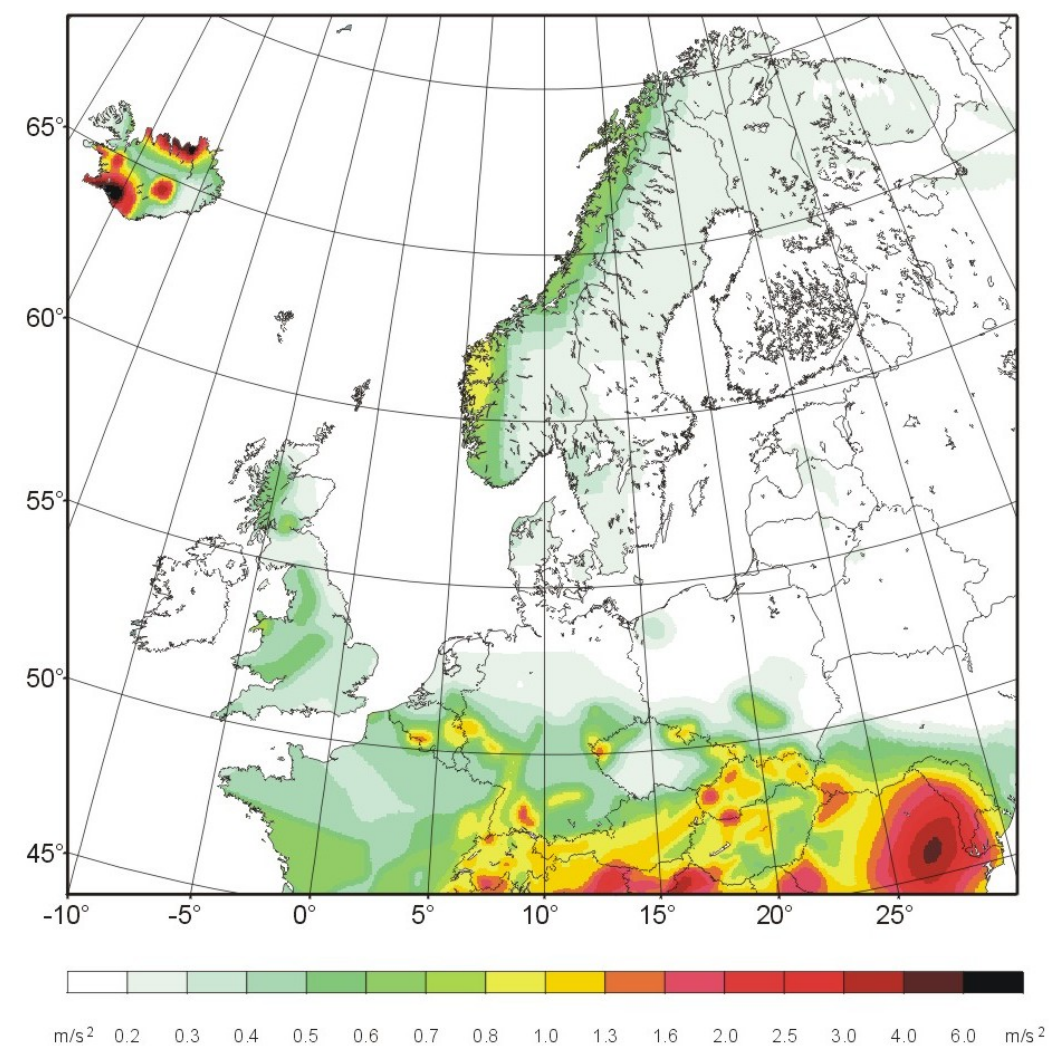

Fig. 1. Seismic hazard map of northern Europe

The most frequent dynamic loads affecting hydroengineering structures in Poland include vibrations caused by heavy road and railway traffic, pilling works and mining tremors (Chmielewski and Zembaty 1998). More destructive dynamic loads, including earthquakes (Jankowski and Mahmoud 2015, 2016, Naderpour et al 2016), may also occur in our country (see Fig. 1), although their frequency of occurrence is relatively low. Considering the possibility of an earthquake taking place, existing and planned structures should be examined, taking into account their behaviour under these extreme excitations, so as to prevent any damage (see also Falborski et al 2012, 
Falborski, Jankowski 2013). The most crucial elements of hydroengineering structures are water gates. With their failure, the whole spillway needs to be evacuated and the loss in energy as well as water retention is immense. The damage done to them by an earthquake does not need to be substantial: even a small leak following a minor unsealing can prove fatal with the passing of time. The recent earthquakes in Poland can be used as examples of such situations (Zembaty et al 2005a). Moreover, there are also a number of places where mining tremors occur almost daily because of the mining industry. This applies mainly to the Legnica-Głogów Industrial District and the Górny Śląsk Coal Basin.

In this study, an example of a steel radial gate has been analyzed. As far as the water gates are concerned, it is among the most popular solutions because of to its relatively small weight, compared to plain gates (Boretti 1968). The aim of the research was to analyse a steel radial gate and its dynamic properties under extreme excitations caused by earthquakes or mining tremors. The analysis aimed to determine whether the gate is vulnerable to dynamic loading. The resulting free vibration frequencies and eigenmode shapes constituted a fundamental basis for further dynamic excitation analysis. In order to obtain meaningful results, a modal analysis of the structure subjected to different water levels was conducted.

\section{Models}

Several models of the steel radial were been designed to examine the influence of different water level pressures on the resulting eigenmodes. All structural members were modelled using shell elements with detailed geometry representing a real structure (see Fig. 2). Each model had the same geometry and boundary conditions, the only difference being the way in which they were loaded by the added weight of water.

The added water mass was calculated using formulas provided by Anami et al (2012). On this basis, a water mass to gate mass ratio was calculated. Different water levels were used to determine the most vulnerable state of the working steel water gate. The gate mass was 5.38 t. Depending on the water level, different mass ratios were obtained. The ratio value is dependent on the inertia moment of the structure, the distance between the bearing and the water level and how deep the gate itself is submerged in water. The total added water mass, as well as the ratio for each loading case, is presented in Table 1.

Table 1. Water to gate mass ratio and total water mass

\begin{tabular}{|c|c|c|c|c|c|c|c|c|c|c|c|c|c|}
\hline Level & $0 \%$ & $10 \%$ & $20 \%$ & $25 \%$ & $30 \%$ & $40 \%$ & $50 \%$ & $60 \%$ & $70 \%$ & $75 \%$ & $80 \%$ & $90 \%$ & $100 \%$ \\
\hline ratio & 0.00 & 0.05 & 0.20 & 0.32 & 0.46 & 0.84 & 1.33 & 1.95 & 2.7 & 3.11 & 3.56 & 4.53 & 5.62 \\
\hline water mass [t] & 0.00 & 0.26 & 1.07 & 1.70 & 2.48 & 4.51 & 7.2 & 10.52 & 14.5 & 16.72 & 19.13 & 24.38 & 30.19 \\
\hline
\end{tabular}

The designed maximum water accumulation level is $4.3 \mathrm{~m}$. The bearing is designed to be $1 \mathrm{~m}$ below the upper water level. The arms are of the same length of 
$6.5 \mathrm{~m}$. The main bearing beams are $2 \mathrm{~m}$ apart counted by the arc length. The plate used in all models is $7 \mathrm{~mm}$ thick, which is the bare minimum required for such structures. The grate consists of 4 vertical I1 80 profile beams and 2 vertical C180 profile beams, 3 horizontal C80 beams and $3 \mathrm{C} 140$ profile horizontal beams. The structure is additionally supported by two horizontal main beams modelled with I360 profiles. The whole structure is based on 4 C180 profile main arms supported by C140 diagonal and vertical beams. The following material properties of steel were used in the analysis: Young's modulus: $210 \mathrm{GPa}$, Poisson's ratio: 0.3 and density: $7800 \mathrm{~kg} / \mathrm{m}^{3}$.

An important part of the numerical model is related to boundary conditions. Because of to the possible movement between the radial gate and weir pillars, horizontal displacement was allowed. It is also important to mention that the gate cannot move from its bearings (in such a case, a major disaster could take place). Therefore, two types of boundary conditions were applied in the model. The first one includes fixed displacements in the bearings with free rotations. The second boundary condition blocks the vertical displacement (since the gate rests on the weir crown blocking vertical downward displacements). It is also important to note that only two ties were applied as a simplification.

\section{Analysis}

The modal analysis was conducted for the numerical model of the structure shown in Fig. 2. In total, thirteen different water levels were considered. For each of them, a modal analysis was conducted resulting in 10 eigenmode frequency values. Different water levels, as well as the positioning of the horizontal beams, are shown in Fig. 3. The analysis was conducted with the assumption of free vibrations and therefore no damping has been taken into account in the modelling process.

The analysis was conducted applying the Lanczos method, which is an algorithm used to find the eigenmodes and eigenfrequencies of a structure. Further information about the method and the eigenproblem can be found in the book by Chmielewski and Zembaty (1998), Chopra (1995) and in various other publications.

The most frequent loading condition would be the one representing the maximum level of accumulation, since most hydroengineering structures are designed to operate with the maximum water level for the highest energy production. Other loading cases occur rather seldom, but it is a essential issue to consider all possible scenarios in order to identify the most unfavourable conditions. A situation where no water is present before the gate can occur during renovation or maintenance works in the reservoir. Lower water levels are often the result of a flood prevention mechanism which consists in emptying the reservoir to reduce the flood wave.

Examples of the results of the modal analysis, in the form of eigenmode shapes for a water level of $100 \%$ of section length, are presented in Figs 4-8 (the general shapes are the same for each case, varying only in frequency values). The values of eigenfrequencies for the first 5 eigenmodes for all cases are summarized in Table 2. 


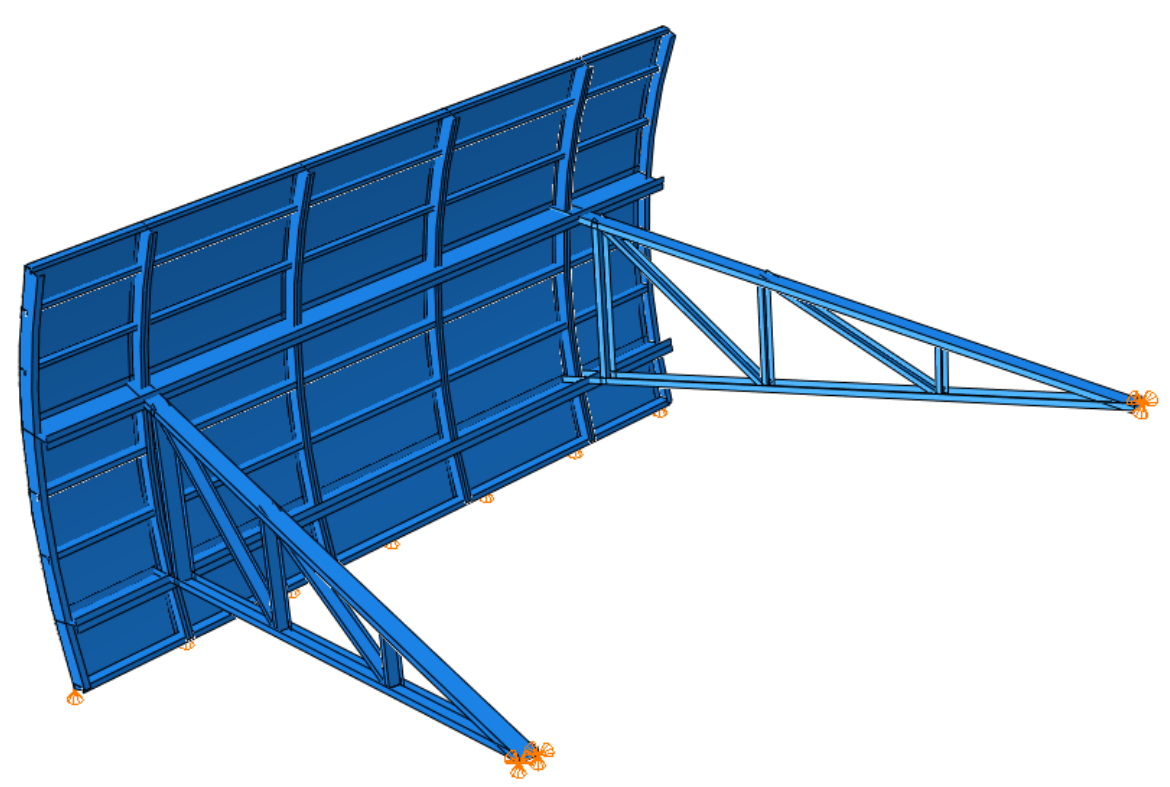

Fig. 2. 2 FE model with boundary conditions

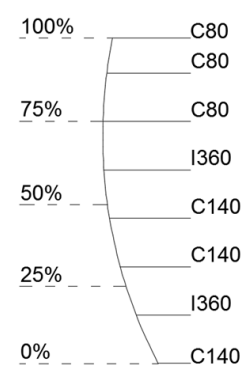

Fig. 3. Sketch of pressure levels and beam profiles (percentage values refer to the length of the section instead of water height)

The resulting frequencies for all eigenmodes are also presented in a graphic form in Fig. 9.

The results shown in Table 2 indicate that all frequencies are high, except those corresponding to first mode. Single digit frequencies suggest that the given eigenmode might be vulnerable to earthquakes, since most of the earthquake-generated energy is transmitted in the $0.5-5 \mathrm{~Hz}$ range (see, Zembaty et al $2005 \mathrm{~b}$, for example). Therefore, the most important eigenmode is the first one, for which displacement direction is perpendicular to the pillars, as shown in Fig. 4. This could result in serious damage to the gate itself, starting with unsealing and even leading to a significant deformation causing the loss of retention. 


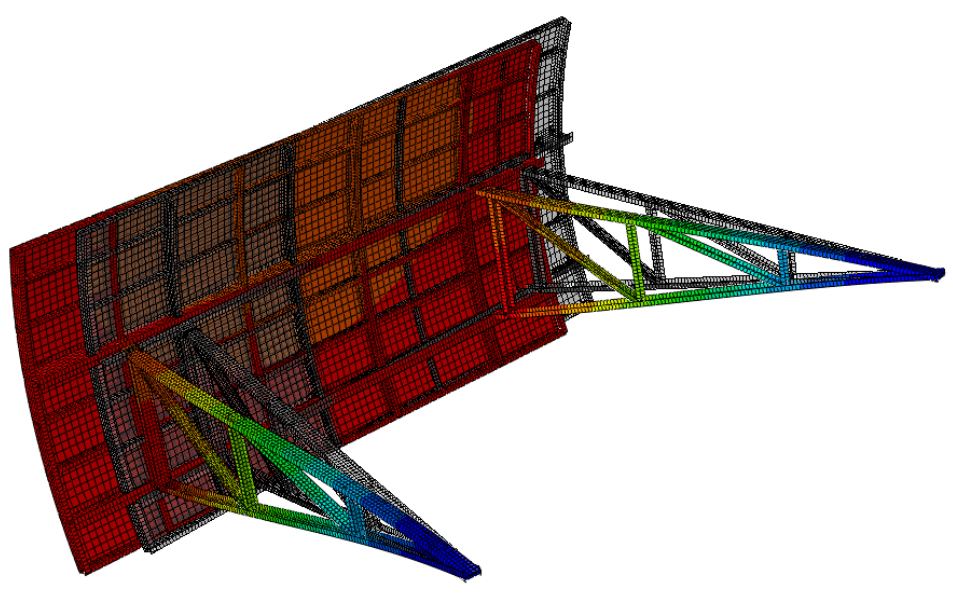

Fig. 4. First eigenmode shape. Frequency $0.87 \mathrm{~Hz}$

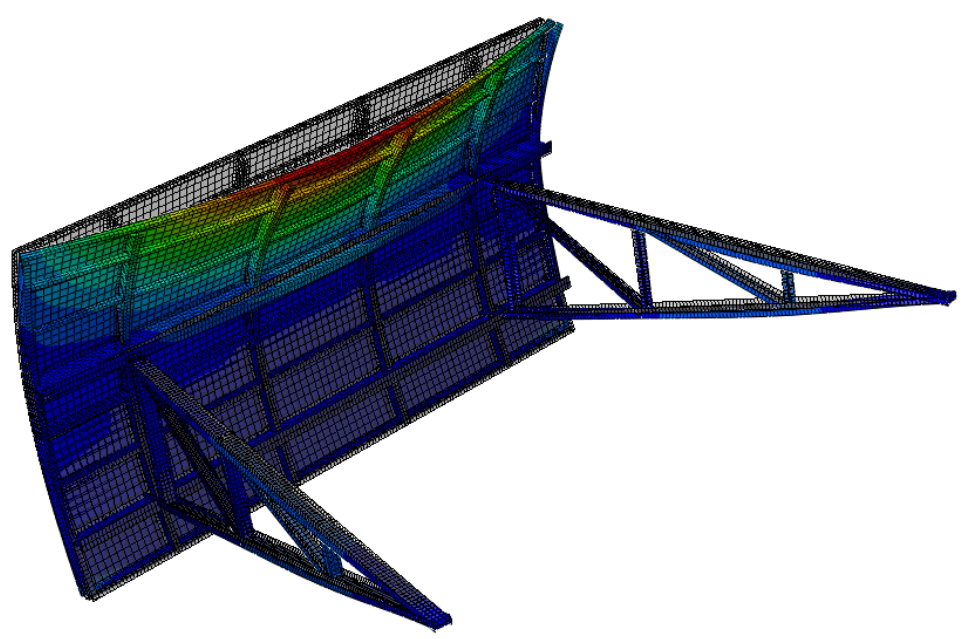

Fig. 5. Second eigenmode shape. Frequency $5.33 \mathrm{~Hz}$ 


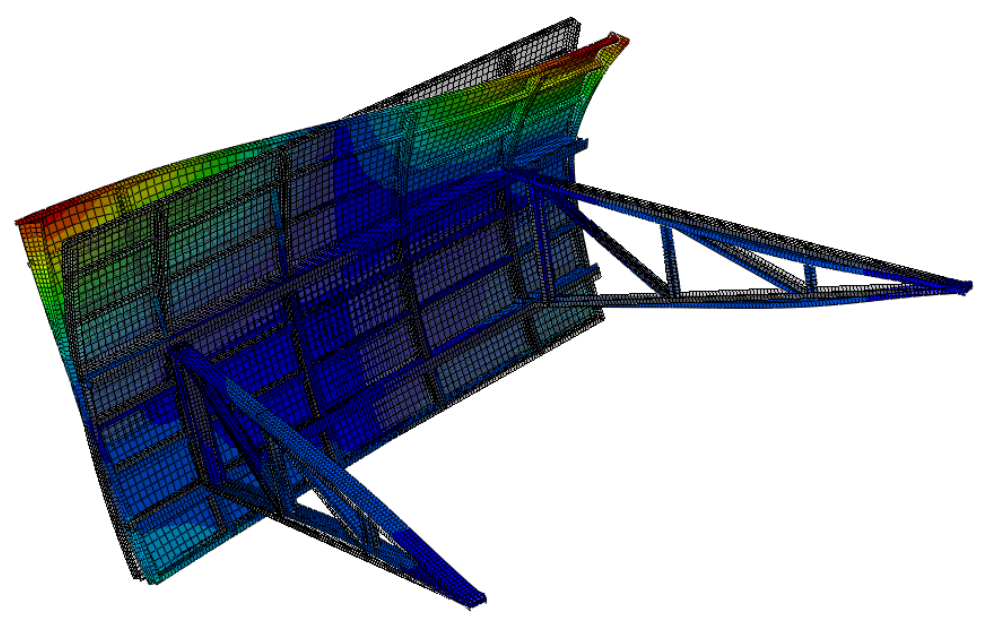

Fig. 6. Third eigenmode shape. Frequency $6.51 \mathrm{~Hz}$



Fig. 7. Fourth eigenmode shape. Frequency $8.29 \mathrm{~Hz}$ 


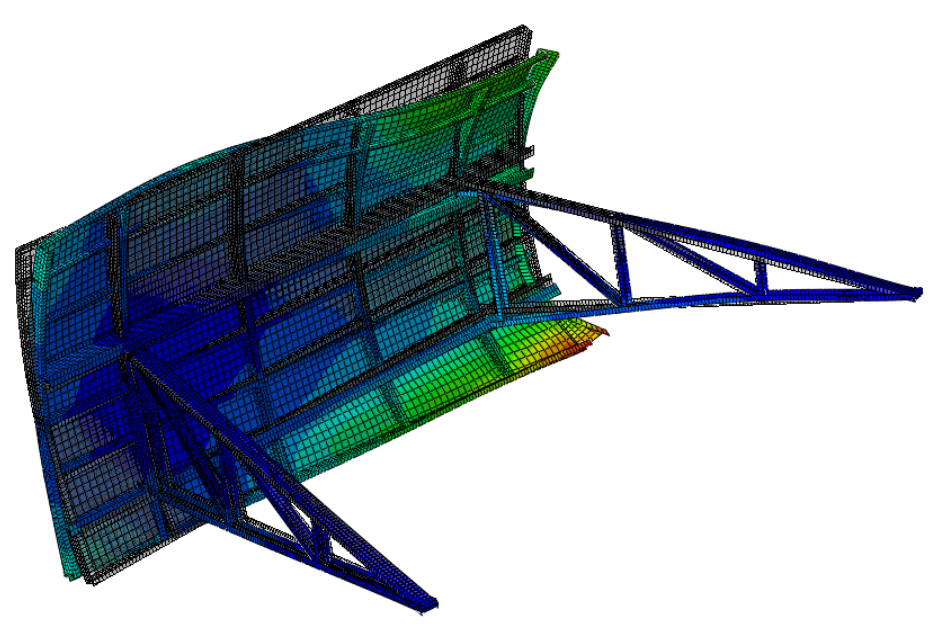

Fig. 8. Fifth eigenmode shape. Frequency $8.99 \mathrm{~Hz}$

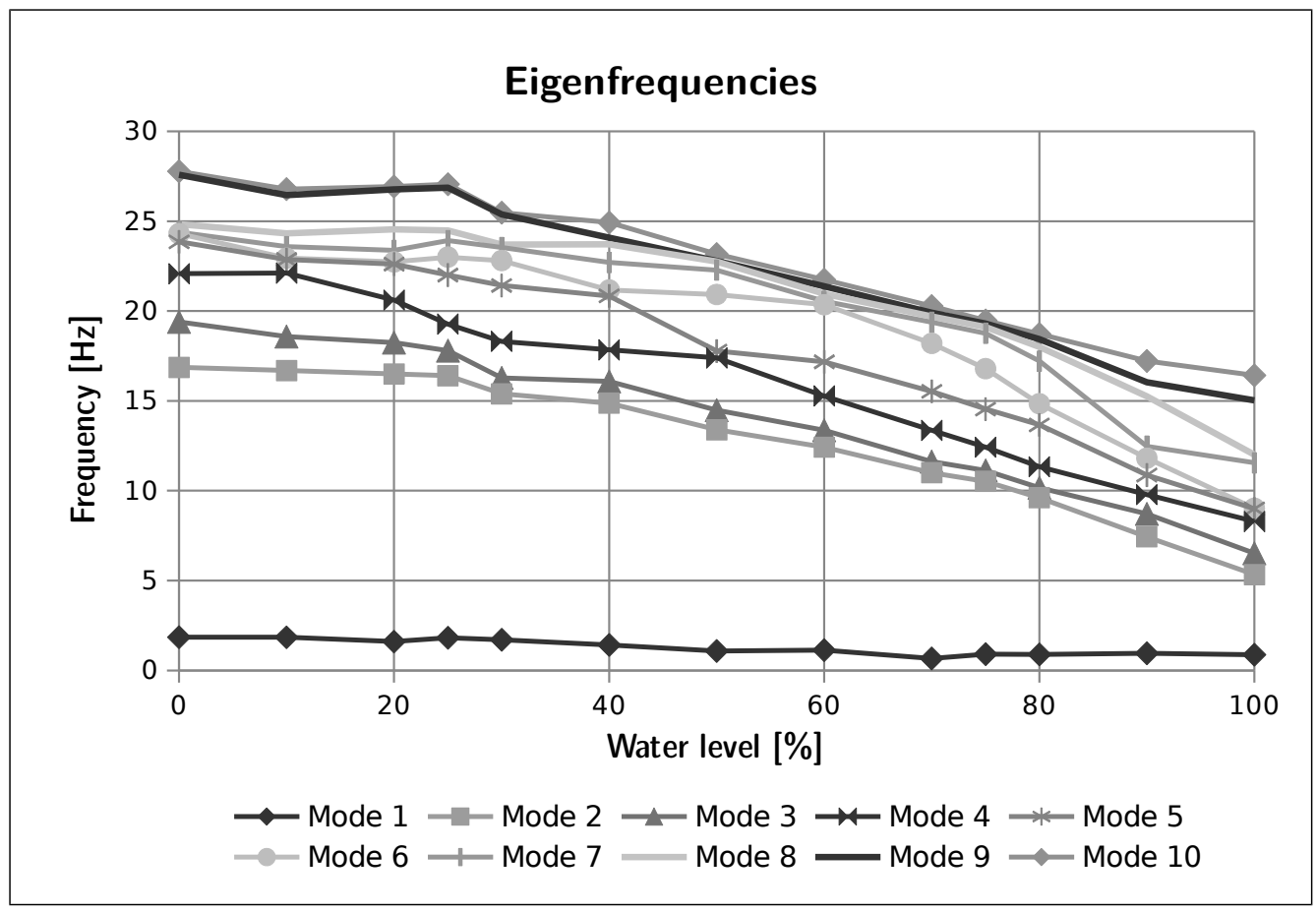

Fig. 9. Eigenmode frequencies for different water levels 
Table 2. 2 First 5 eigenfrequencies for different water levels

\begin{tabular}{|c|c|c|c|c|c|c|c|c|c|c|c|c|c|}
\hline Level & $0 \%$ & $10 \%$ & $20 \%$ & $25 \%$ & $30 \%$ & $40 \%$ & $50 \%$ & $60 \%$ & $70 \%$ & $75 \%$ & $80 \%$ & $90 \%$ & $100 \%$ \\
\hline Mode & {$[\mathrm{Hz}]$} & {$[\mathrm{Hz}]$} & {$[\mathrm{Hz}]$} & {$[\mathrm{Hz}]$} & {$[\mathrm{Hz}]$} & {$[\mathrm{Hz}]$} & {$[\mathrm{Hz}]$} & {$[\mathrm{Hz}]$} & {$[\mathrm{Hz}]$} & {$[\mathrm{Hz}]$} & {$[\mathrm{Hz}]$} & {$[\mathrm{Hz}]$} & {$[\mathrm{Hz}]$} \\
\hline 1 & 1.85 & 1.84 & 1.60 & 1.82 & 1.70 & 1.41 & 1.08 & 1.13 & 0.66 & 0.91 & 0.89 & 0.95 & 0.87 \\
\hline 2 & 16.86 & 16.69 & 16.50 & 16.40 & 15.39 & 14.87 & 13.39 & 12.42 & 11.00 & 10.52 & 9.61 & 7.43 & 5.33 \\
\hline 3 & 19.40 & 18.58 & 18.24 & 17.80 & 16.28 & 16.08 & 14.48 & 13.36 & 11.62 & 11.13 & 10.17 & 8.70 & 6.51 \\
\hline 4 & 22.08 & 22.11 & 20.61 & 19.27 & 18.31 & 17.84 & 17.39 & 15.27 & 13.36 & 12.42 & 11.33 & 9.78 & 8.29 \\
\hline 5 & 23.85 & 22.86 & 22.61 & 22.00 & 21.42 & 20.84 & 17.77 & 17.17 & 15.53 & 14.54 & 13.66 & 10.87 & 8.99 \\
\hline
\end{tabular}

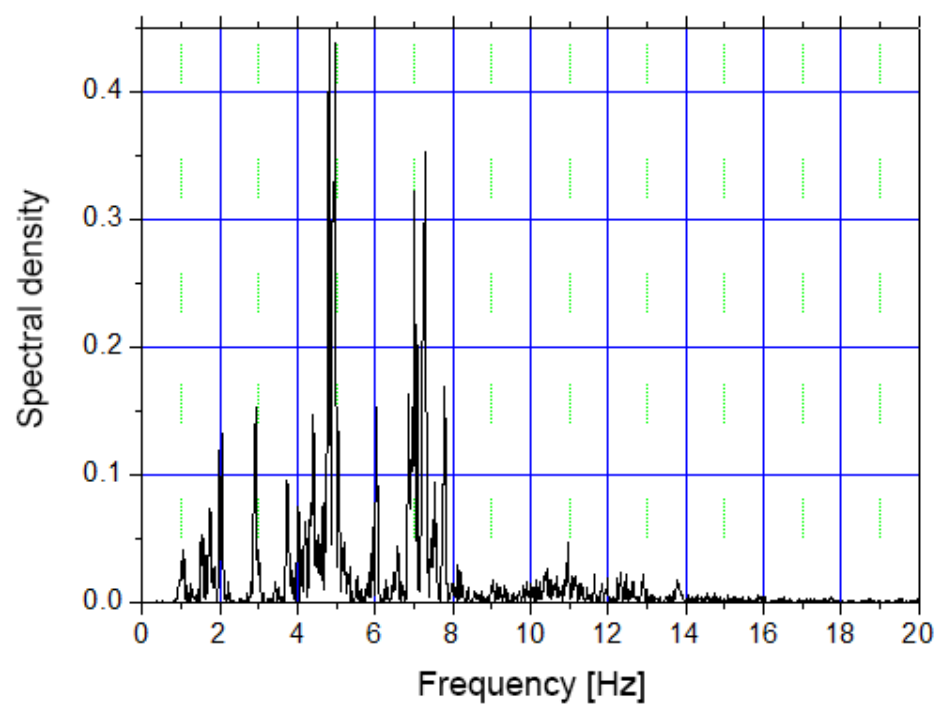

Fig. 10. Fourier spectrum for the 1st shock of the earthquake from September 21, 2004 (Zembaty et al 2005a)

Moreover, the results show how big the influence of water is (see Table 2 and Fig. 9 ). The difference in frequency is clearly affected by the additional mass of water. The general trend shows that the higher the water level is and the more the gate is submerged under water, the lower the frequency value becomes. For the situation when the gate is fully submerged, the frequencies drop by as much as $64 \%$ compared to the case when there is no water at all.

To highlight the significance of the results, the eigenfrequencies were compared with the excitation frequencies of the earthquake which took place in northern Poland on September 21, 2004 (see Fig. 10 and Fig. 11). The earthquake was moderate, but damage to various structures were reported (see Zembaty et al 2005a). It can be seen from Fig. 10 and Fig. 11 that the largest amount of seismic energy was transferred within the frequency range of $1-8 \mathrm{~Hz}$. Since the first natural frequency of the analyzed radial gate (see Table 2) falls within this range, this structure can be vulnerable to seismic loading. 


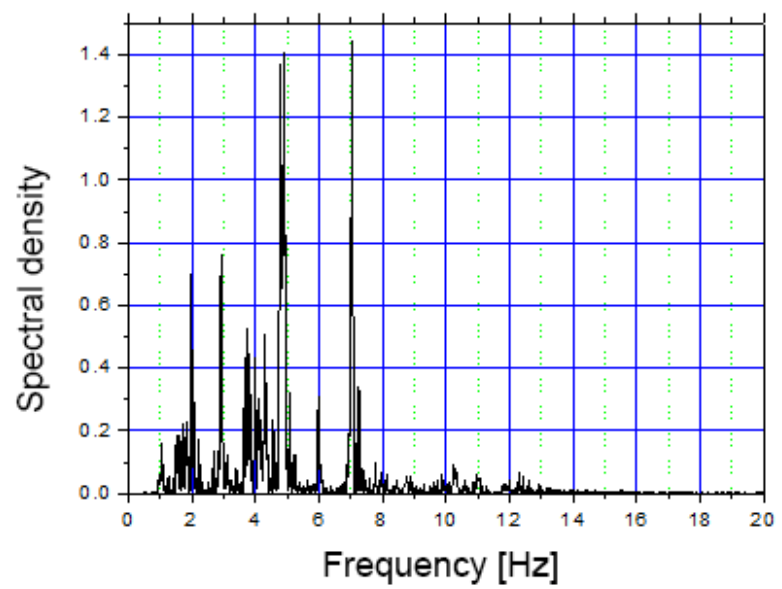

Fig. 11. Fourier spectrum for the 2nd shock of the earthquake from September 21, 2004 (Zembaty et al 2005a)

\section{Conclusions}

The influence of various water levels, in the form of additional water mass, on a chosen model of a steel radial gate was analyzed in this study. The modal analysis was conducted for thirteen different cases. Each of them resulted in 10 eigenmode frequency values for a total of 130 eigenfrequencies.

The results of the study show that changes in the water level have a considerable influence on eigenmode frequencies. The general trend indicates that the higher the water level is, the lower the frequency becomes, and the reduction in the frequency value can be substantial.

All frequencies obtained during by modal analysis are relatively high, except for the first eigenmode and the maximum water accumulation case. Moreover, it is important to mention that the frequency values for the first eigenmode being in the $0.5-5$ $\mathrm{Hz}$ range for all cases means that the structure can be highly vulnerable to dynamic loads caused by earthquakes or mining tremors. The results indicate, therefore, that the steel radial gate can suffer some damage when exposed to these dynamic loads. In additions, a comparison of the Fourier spectra shown in Fig. 10 and Fig. 11 with the free vibration frequencies of the structure makes it clear that radial gates should be analyzed with regard to seismic loading.

The present study investigated the susceptibility of steel gates to dynamic loads. Since the field of interest is relatively new, it can be considered the first step in researching the effects of extreme dynamic loads, including earthquakes, on steel radial gates. This study itself is already a strong basis for further investigations, which are planned to be conducted. These investigations will also have to include a larger spectrum of gates with different geometry, boundary conditions or even materials used. 


\section{Acknowledgements}

Calculations were carried out at the Academic Computer Centre in Gdańsk. The authors would like to thank TASK CI for the opportunity to use the ABAQUS software.

\section{References}

Anami K., Ishii N., Knisely C. (2012) Added mass and wave radiation damping for flow-induced rotational vibrations of skinplates of hydraulic gates, Journal of Fluids and Structures, 35, 213-228.

Boretti Z. (1968) Steel Structures in Water Engineering, Warszawa, Arkady (in Polish).

Cai YQ., Zhang K. (2011) Study of Modal Parameter Identification from Ambient Vibration on a Deep Radial Gate, Applied Mechanics and Materials, 105-107, 511-517.

Chmielewski T., Zembaty Z. (1998) Fundamentals of Structural Dynamics, Warszawa, Arkady (in Polish).

Chopra A. (1995) Dynamics of Structures: Theory and Applications to Earthquake Engineering, New Jersey, Prentice Hall, Englewood Cliffs.

Falborski T., Jankowski R., Kwiecień A. (2012) Experimental study on polymer mass used to repair damaged structures, Key Engineering Materials, 488-489, 347-350.

Falborski T., Jankowski R. (2013) Polymeric bearings - a new base isolation system to reduce structural damage during earthquakes, Key Engineering Materials, 569-570, 143-150, .

Jankowski R., Mahmoud S. (2015) Earthquake-Induced Structural Pounding, Springer, Switzerland.

Jankowski R., Mahmoud S. (2016) Linking of adjacent three-storey buildings for mitigation of structural pounding during earthquakes, Bulletin of Earthquake Engineering, 14, 3075-3097.

Liu J. L., Fang X., Wang Z. Z., Sun D. X. (2012) Simulations of Natural Vibration Characteristics of Large-Size Radial Gate with Three Arms Considering Fluid-Solid Coupling, Applied Mechanics and Materials, 50-51, 200-204.

Naderpour H., Barros R. C., Khatami S. M., Jankowski R. (2016) Numerical study on pounding between two adjacent buildings under earthquake excitation, Shock and Vibration, Vol. 2016, Article ID 1504783.

Pani P., Bhattacharyya S. (2008) Hydrodynamic pressure on a vertical gate considering fluid-structure interaction, Finite Elements in Analysis \& Design, 44, 759-766.

Wójcicki Z., Kostecki S., Grosel J. (2016) Operational Modal Analysis of Weir on Odra River in Poland, Procedia Engineering, 153, XXV Polish-Russian-Slovak Seminar"Theoretical Foundation of Civil Engineering", 874-881.

Zembaty Z., Cholewicki A., Jankowski R., Szulc J. (2005a) Earthquakes of September 21, 2004 in north eastern Poland and their effects on structures, Inżynieria i Budownictwo, 61 (1), 3-9 (in Polish).

Zembaty Z., Jankowski R., Cholewicki A., Szulc J. (2005b) Earthquake of November 30, 2004 in Podhale and its effects on structures, Inżynieria i Budownictwo, 61 (9), 507-511 (in Polish).

1. na str. 39 jest jeszcze Zembaty 2005 ma być a czy b 